\title{
RESEARCH
}

Open Access

\section{Trends of loss of peripheral muscle thickness on ultrasonography and its relationship with outcomes among patients with sepsis}

Vijay Hadda ${ }^{1 *}$ (D, Rohit Kumar ${ }^{1}$, Gopi Chand Khilnani ${ }^{1}$, Mani Kalaivani ${ }^{2}$, Karan Madan ${ }^{1}$, Pawan Tiwari ${ }^{1}$, Saurabh Mittal', Anant Mohan', Ashu Seith Bhalla ${ }^{3}$ and Randeep Guleria ${ }^{1}$

\begin{abstract}
Background and aims: Data regarding trends of muscle loss on ultrasonography (USG) and its relationship with various outcomes among critically ill patients is limited. This study aimed to describe the trends of loss of muscle thickness of the arm and thigh (assessed using USG) and to determine the relationship between loss of muscle thickness and in-hospital and post-discharge outcomes.

Methods: Muscle thickness of 70 patients with sepsis was measured at the level of the mid-arm and mid-thigh using bedside USG on days 1, 3, 5, 7, 10 and 14 and then weekly till discharge or death. Patients were followed up for 90 days after discharge.

Results: The muscle thickness (mean \pm SD) at the level of the mid-arm and mid-thigh on day 1 was $23.13 \pm 4.83$ $\mathrm{mm}$ and $31.21 \pm 8.56 \mathrm{~mm}$, respectively. The percentage muscle thickness [median (min, max)] decline at the mid-arm and mid-thigh was $7.61(-1.51,32.05) \%$ and $10.62(-1.48,32.06) \%$, respectively on day 7 as compared to baseline $(p<0.001)$. The decline in muscle thickness at the mid-arm and mid-thigh were higher among non-survivors compared to survivors at all time points. Also, the decline in muscle thickness was significantly higher among patients with worse outcome at day 90. Patients with ICU-acquired weakness also had significantly higher decline in muscle thickness $(p<0.05)$. Early decline (from day 1 to day 3 ) in muscle thickness was associated with in-hospital mortality. The probability of death by day 14 was higher for patients who had early decline (from day 1 to day 3 ) in muscle thickness of $\geq 6.59 \%$ and $\geq 5.20 \%$ at the mid-arm [HR $7.3(95 \% \mathrm{Cl} 1.5,34.2)$ ] and the mid-thigh [HR 8 . $1(95 \% \mathrm{Cl} 1.7,37.9)]$, respectively. Decline in thickness from day 1 to day 3 was a good predictor of in-hospital mortality with area under the curve (AUC) of 0.81 and 0.86 for arm and thigh muscles, respectively.
\end{abstract}

Conclusions: Critically ill patients with sepsis exhibit a gradual decline in muscle thickness of both the arm and thigh. Decline in muscle thickness was associated with in-hospital mortality. USG has a potential to identify patients at risk of worse in-hospital and post-discharge outcomes.

Keywords: Ultrasonography, Muscle thickness, Critical illness, ICU, Sepsis, Outcome

\footnotetext{
* Correspondence: vijayhadda@yahoo.com

${ }^{1}$ Department of Pulmonary Medicine and Sleep Disorders, All India Institute

of Medical Sciences, New Delhi, India

Full list of author information is available at the end of the article
}

(c) The Author(s). 2018 Open Access This article is distributed under the terms of the Creative Commons Attribution 4.0 International License (http://creativecommons.org/licenses/by/4.0/), which permits unrestricted use, distribution, and reproduction in any medium, provided you give appropriate credit to the original author(s) and the source, provide a link to the Creative Commons license, and indicate if changes were made. The Creative Commons Public Domain Dedication waiver (http://creativecommons.org/publicdomain/zero/1.0/) applies to the data made available in this article, unless otherwise stated. 


\section{Background}

Weakness of skeletal muscles is among the major risk factors associated with increased duration of stay in intensive care units (ICU) and hospital, in-hospital mortality and physical disability $[1,2]$. This weakness is a result of muscle wasting due to immobility, sepsis, organ dysfunction, drugs and systemic inflammation [3]. Critically ill patients with sepsis are at risk of developing muscle wasting [4]. However, accurate quantification of muscle wasting remains a challenge among these patients [5]. Assessment of muscle wasting using clinical examination and anthropometry has limitations in this setting [1]. Imaging of these muscles with computer tomographic (CT) scan, magnetic resonance imaging (MRI), or dual energy X-ray absorptiometry (DEXA) scan is though accurate but not practical in patients admitted to ICU [1]. Bioelectrical impedance analysis can also be used to estimate muscle mass; however, it can be affected by the variable hydration status and requires special apparatus. Therefore, a sensitive, reliable and safe tool for measurement of loss of muscle objectively is required.

Ultrasonography (USG) has been used as a tool for assessment of muscle thickness in ICU setting [4, 6, 7]. Muscle thickness has been shown as a good surrogate of muscle mass and can be measured using USG with excellent intra- and inter-observer reliability [6, 8, 9]. Non-invasive nature and bedside availability makes USG an ideal tool for serial assessment of thickness of peripheral muscles. Serial assessment can provide useful information regarding the muscle loss in relation to time among critically ill patients in ICU. However, majority of published studies on assessment of muscle thickness in ICU are cross-sectional in design [7]. There are only few studies which have used USG for measurement of muscle thickness at standardized time points for comparison [10-12]. Muscle dysfunction assessed by various tools has been associated with both in-hospital as well as post-discharge mortality and morbidity $[1,2]$. USG can be used for serial assessment of muscle dysfunction; however, there is a lack of data regarding relationship between change in muscle thickness measured by USG and in-hospital and post hospital discharge outcomes.

We planned this prospective study to evaluate the trends of change in muscle thickness of the arm and thigh among critically ill patients with sepsis. We also sought to describe the relationship between change in muscle thickness and in-hospital and day-90 outcome among these patients.

\section{Materials and methods}

\section{Study design, patients and setting}

This prospective study was conducted between March 2015 and December 2016 at a tertiary care teaching hospital. All adult (age $\geq 18$ years) patients admitted under
Pulmonary Medicine services with a diagnosis of sepsis with medical illness (non-surgical) were eligible for inclusion in the study. The diagnosis of sepsis was based on the criteria proposed by SCCM/ESICM/ACCP/ATS/ SIS International Sepsis Definitions Conference [13]. Criteria included the presence of infection (proven or suspected) plus presence of systemic inflammatory response syndrome (SIRS). SIRS may be recognized by the presence of any one of the following (but limited to): temperature more than $38^{\circ} \mathrm{C}$ or less than $36^{\circ} \mathrm{C}$, heart rate $>90 / \mathrm{min}$, respiratory rate $>30 / \mathrm{min}$, altered mental status, positive fluid balance, leukocytosis or leukopenia, more than $10 \%$ of immature neutrophils and increased $\mathrm{C}$-reactive protein or procalcitonin. Patients with any known neuro-muscular diseases such as myopathy, neuropathy, or stroke; with dressing over or imputed right limb; with recent (within 3 months) hospitalization and need of ventilator support or home ventilation; who transferred from other hospital after stay of more than $24 \mathrm{~h}$; and who refused to give consent for the study were excluded. Also, patients with duration of hospital stay less than $72 \mathrm{~h}$ (due to death or discharge) were excluded from the study.

\section{Equipment and operator}

For this study, we used Siemens ACUSON X300 (Siemens Health Care, Germany) machine for measurement of the muscle thickness. Muscle thickness measurements were done using B-mode of USG using $5.0-13.0 \mathrm{MHz}$ (megahertz) linear array probe (VF 13-5). All measurements were taken by a single operator (RK) who was trained in using bedside USG in ICU.

\section{Site, posture and measurement technique}

Measurements of muscle thickness were done on the right side, at the level of the mid-arm and mid-thigh. All measurements were done in supine position, unless contra-indicated. For the arm, the flexor compartment (biceps brachii and coracobrachialis) and, for thigh, the extensor compartment (quadriceps muscles) of muscles were selected. The measurements of the muscle thickness of the flexor compartment of the arm and quadriceps muscles were performed following similar protocol used by Campbell and colleagues in 1997 and recently validated by us $[6,8,9]$. Briefly, a circumferential mark was applied at the midway between the greater tuberosity and the tip of the olecranon process of the humerus. Similarly, a circumferential mark was applied at the midway between the tip of the greater trochanter and the lateral joint line of the knee. The linear array USG probe was placed on the anterior aspect of this circumferential line, perpendicular to 
the skin, and the probe was moved along the line drawn till a suitable image was obtained. Keeping the focus on the suitable image, a point corresponding to the centre of the probe was marked with a vertical line. Same procedure was done for the arm and thigh. This vertical point on the circumferential line was used as the reference point for all subsequent measurements.

Arm muscle thickness was measured while the upper limb relaxed, lying parallel to the body, the elbow extended and the palm facing the ceiling. Thigh muscle thickness was measured while the leg resting straight, the knee extended and the great toe facing the ceiling. The measurements of the muscle thickness was done using built-in callipers on the real-time frozen image (Additional file 1).

\section{Muscle thickness measurement schedule}

The measurements of the muscle thickness at both the sites were recorded on days $1,3,5,7,10$ and 14 and subsequently on a weekly basis, till discharge or death of the patient.

\section{Outcome measurement}

In-hospital outcome parameters including length of stay (LOS) in the hospital and ICU, time spent on ventilator and death or survival were recorded. Whenever the patients were awake and cooperative during the time of the USG examination, a clinical assessment of the muscle strength was also done using Medical Research Council (MRC) sum score. Patients with an MRC sum score of $<48$ were classified as having ICU-acquired weakness (ICU-AW) [14]. Post discharge, survivors were contacted telephonically on day 90 . They were asked regarding worsening of condition requiring unscheduled visit to hospital or emergency or hospitalization. For the analysis of 90-day outcome, death or worsening of condition leading to unscheduled visit to hospital or emergency or hospitalization was labelled as poor outcome and survivors without any of these were classified as stable outcome.

\section{Statistical analysis}

The sample size of 70 was based only on feasibility. Data analysis was performed with Stata14.0 (StataCorp LP, College Station, TX 77845, USA). Measurements taken till day 7 (days 1, 3, 5 and 7) and last measurement (irrespective of day) were included in the final analysis as there were only 16, 11, 3 and 2 patients on days 10,14, 21 and 28, respectively. Data were expressed as number (\%) or mean \pm standard deviation (SD) or median with inter-quartile range (IQR) as deemed appropriate. We used marginal model of Generalized Estimating Equation (GEE) for assessing the magnitude of change in the muscle thickness at each time point (days 1, 3, 5 and 7) and also to show whether loss of muscle thickness was more during early or later part of hospital stay. Percentage loss of thickness was compared between two groups of various outcomes such as in-hospital mortality, ICU-AW and 90-day outcome at each time points using Wilcoxon rank sum test since the data was not normally distributed.

Receiver operating characteristics (ROC) curve analysis was used to compare the predictive ability of loss (\%) of muscle thickness of the arm and thigh (at day 3 with respect to day 1) and Acute Physiology and Chronic Health Evaluation (APACHE)-II and Sequential Organ Failure Assessment (SOFA) (at day 3) scores against in-hospital mortality. ROC analysis showed that a cutoff of decline in muscle thickness of more than or equal to $6.59 \%$ for the arm and $5.20 \%$ for the thigh can predict survival. Kaplan-Meier curve was used to depict probability of survival over time between the categories (derived by ROC analysis) of decline in percent muscle thickness of the arm and thigh followed by log-rank test to compare these survival probabilities. Cox proportional hazards model was used to calculate the hazards of mortality (95\% CI) associated with decline in percent muscle thickness of the arm and thigh of $\geq 6.59 \%$ and $\geq 5.20 \%$, respectively. Logistic regression analysis was used to find the odds associated with decline in percent muscle thickness of the arm and thigh of $\geq 6.59 \%$ and $\geq 5.20 \%$, respectively, on prolonged ( $>2$ weeks) mechanical ventilation and ICU stay. The $p$ value of $<0.05$ was considered as statistically significant.

\section{Ethical aspect}

The study was conducted following guidelines for biomedical research involving human subjects [15, 16]. Study protocol was approved by Institutional Ethics Committee.

The manuscript is written according to STROBE statement for observation studies.

\section{Results}

There were 96 eligible patients who were evaluated on day 1. Among these, 26 (19 died and 7 discharged) patients were excluded before evaluation on day 3 . The final study cohort included 70 (45 male) patients admitted with sepsis. The flow of participants in the study is shown in Fig. 1. Study patients had severe illness with APACHE (mean \pm SD) and SOFA (mean \pm SD) scores of $17.17 \pm 4.42$ and $5.71 \pm 2.05$, respectively. The baseline features of the study cohort are summarized in Table 1. 


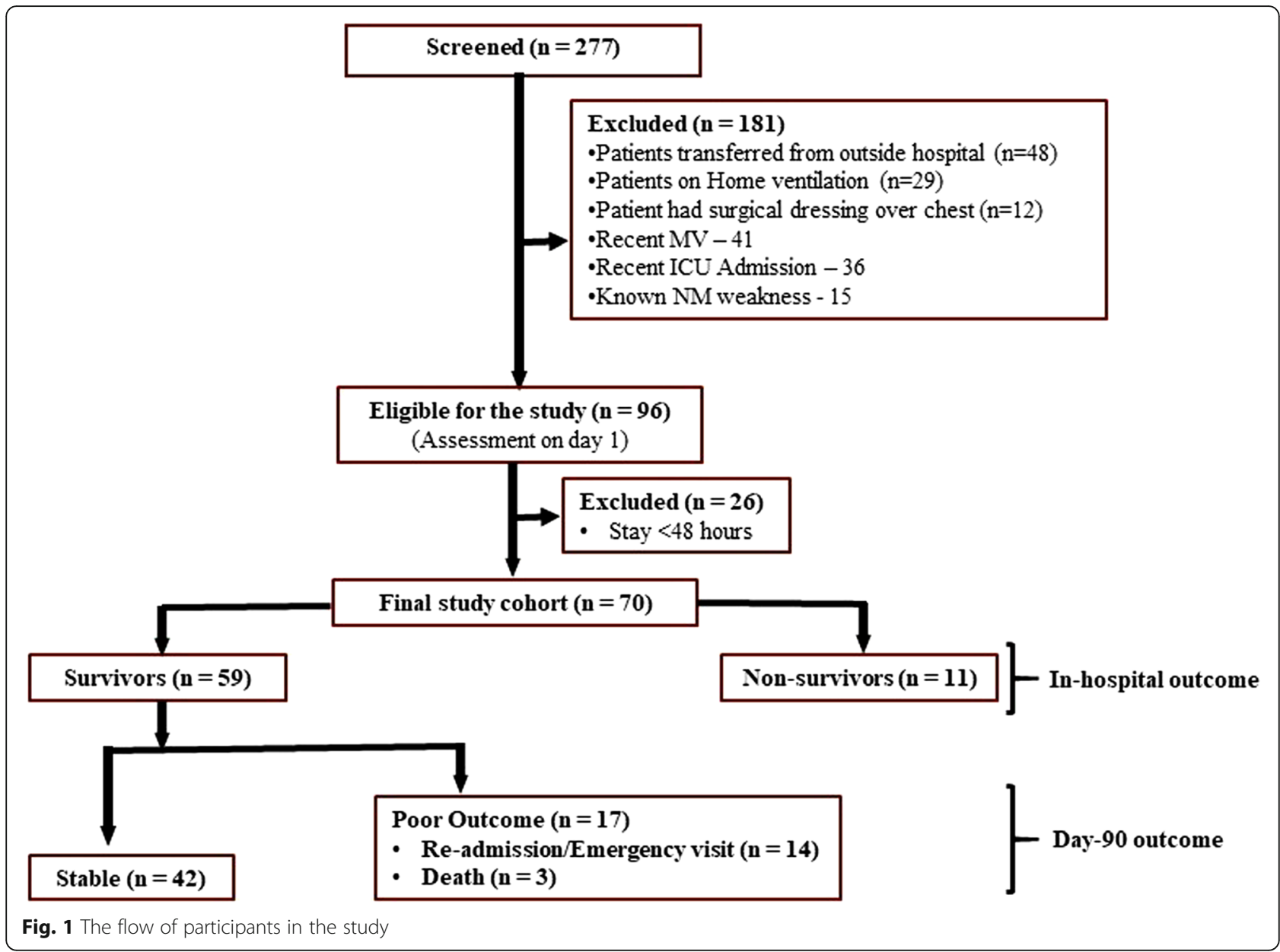

Trends of muscle thickness on USG

The muscle thickness (mean \pm SD) measured at the level of the mid-arm and mid-thigh on day 1 was $23.13 \pm 4.83 \mathrm{~mm}$ and $31.21 \pm 8.56 \mathrm{~mm}$, respectively. The muscle thickness (\%), both at mid-arm and mid-thigh levels, showed a significant decline at each time points of assessment (days 3, 5 and 7 and last assessment) with respect to baseline (Fig. 2).

\section{Loss of muscle thickness and outcomes}

\section{a. In-hospital mortality}

Among the study cohort, there were 11 deaths during hospital stay. At day 1, the mean thickness of arm and thigh muscles was comparable between survivors and non-survivors (Tables 2 and 3). As shown in Tables 2 and 3 , the percentage decline in the muscle thickness of the arm and thigh was higher among non-survivors as compared to survivors at all time-points of assessment.

ROC analysis showed that a cutoff of decline in muscle thickness of more than or equal to $6.59 \%$ for the arm and $5.20 \%$ for the thigh can predict survival
(Fig. 3). As shown in Fig. 4a and b, the probability of survival $(95 \% \mathrm{CI})$ at day 14 was higher with < $6.59 \%[93.3 \%(61.3 \%, 99.0 \%)]$ than $\geq 6.59 \%[60.9 \%$ $(30.4 \%, 81.3 \%)]$ of loss of arm muscle thickness; the hazard of dying with loss of arm muscle thickness of $\geq 6.59 \%$ was 7.3 times (95\% CI 1.5-34.2) higher than their counterparts with $p$ value 0.012 . The probability of survival $(95 \% \mathrm{CI})$ at day 14 with the loss of thigh muscle thickness of $<5.20 \%$ and $\geq 5.20 \%$ was $88.2 \%(60.6 \%, 96.9 \%)$ and $66.3 \%(31.4 \%, 86.4 \%)$, respectively; $p$ value $<0.002$. ROC analysis also revealed that SOFA score was the best predictive tool (shown in Table 4 and Fig. 3) for in-hospital mortality followed by the loss of thigh muscle thickness between day 1 and day 3 .

b. Requirement of mechanical ventilation and stay in ICU

Total duration of ICU stay and requirement of mechanical ventilation ranged from 3 to 31 days and 0 to 31 days, respectively. The mean $( \pm \mathrm{SD})$ of ICU stay and time spent on mechanical ventilation were 
Table 1 Baseline characteristics of the study cohort

\begin{tabular}{|c|c|}
\hline Variables & $\begin{array}{l}\text { Observation } \\
(N=70)\end{array}$ \\
\hline Age (mean $\pm S D$, years) & $55.91 \pm 14.08$ \\
\hline \multicolumn{2}{|l|}{ Gender } \\
\hline Male (\%) & $45(64.3 \%)$ \\
\hline APACHE-II score (mean \pm SD) & $17.17 \pm 4.42$ \\
\hline SOFA score (mean $\pm \mathrm{SD}$, day 1 ) & $5.71 \pm 2.05$ \\
\hline Height (mean \pm SD, cm) & $158.45 \pm 5.89$ \\
\hline Haemoglobin (mean $\pm S D, g m / d l)$ & $12.29 \pm 2.07$ \\
\hline Haematocrit (mean $\pm S D, g m / d l)$ & $39.55 \pm 7.32$ \\
\hline Leukocyte counts (mean \pm SD, per dl) & $13,799 \pm 4998$ \\
\hline $\begin{array}{l}\text { Blood Urea [median (interquartile range), } \\
\mathrm{mg} / \mathrm{dl}]\end{array}$ & $54(13-191)$ \\
\hline $\begin{array}{l}\text { Serum creatinine [median } \\
\text { (interquartile range), } \mathrm{mg} / \mathrm{dl}]\end{array}$ & $0.9(0.3-4.7)$ \\
\hline $\begin{array}{l}\text { Serum bilirubin [median } \\
\text { (interquartile range), mg/dl] }\end{array}$ & $0.6(0.2-3.7)$ \\
\hline Serum albumin (mean \pm SD, gm/dl) & $3.17 \pm 0.49$ \\
\hline Serum calcium (mean $\pm \mathrm{SD}, \mathrm{gm} / \mathrm{dl}$ ) & $8.02 \pm 0.76$ \\
\hline Serum phosphate (mean $\pm S D, g m / d l)$ & $3.27 \pm 1.12$ \\
\hline $\begin{array}{l}\text { Anterior arm muscle thickness } \\
\text { (mean } \pm \mathrm{SD}, \mathrm{mm})\end{array}$ & $23.13 \pm 4.83$ \\
\hline $\begin{array}{l}\text { Quadriceps muscle thickness } \\
\text { (mean } \pm \mathrm{SD}, \mathrm{mm} \text { ) }\end{array}$ & $31.21 \pm 8.56$ \\
\hline \multicolumn{2}{|l|}{ Source of infection } \\
\hline Lower respiratory tract & $67(95.7 \%)$ \\
\hline Urinary tract & $3(4.3 \%)$ \\
\hline \multicolumn{2}{|l|}{ Co-morbidities } \\
\hline COPD & $40(57 \%)$ \\
\hline Asthma & $7(10 \%)$ \\
\hline Bronchiectasis & $7(10 \%)$ \\
\hline Interstitial lung diseases & $2(3 \%)$ \\
\hline
\end{tabular}

$7.24( \pm 5.1)$ days and $3.9( \pm 5.3)$ days, respectively. Odds ratio $(95 \% \mathrm{CI})$ for requirement of prolonged $(\geq$ 2 weeks) mechanical ventilation associated with the decline of $\geq 6.59 \%$ and $\geq 5.20 \%$ of arm and thigh muscle thicknesses was $4.2(0.65,27.6), p=0.131$, and 9.7(1.01, 92.4), $p=0.049$, respectively. Odds ratio $(95 \%$ CI) for prolonged ( $\geq 2$ weeks) ICU stay associated with muscle thickness of $\geq 6.59 \%$ and $\geq 5.20 \%$ of arm and thigh muscle thicknesses was $3.8(0.90,16.1), p=$ 0.067 , and $3.0(0.72,12.4), p=0.132$, respectively.

\section{c. ICU-acquired muscle weakness}

ICU-AW was diagnosed in 15 patients. The comparisons of loss of muscle thickness was done between patients with and without ICU-AW (MRC score $<48$ vs $\geq 48$ ), at different time points (Tables 2 and 3). Median (IQR) percentage decline in muscle thickness of the arm and thigh at day 7 was higher for those who had ICU-AW than those without it.

\section{d. Outcome during 90 days follow-up}

During 90 days follow-up, 17 out of 59 survivors had poor outcome (death-3, emergency visit or re-admission-14) whereas 42 remained stable. The decline in muscle thickness, both the arm and thigh, was higher in patients with poor outcome than in those with stable outcome during 90 days follow-up, which is shown in Tables 2 and 3.

\section{Discussion}

This study showed that USG can be used for demonstration of trends of loss of arm and thigh muscles thickness among patients with sepsis during ICU and hospital stay. Our results demonstrated that patients with sepsis lose approximately $9-10 \%$ of muscle thickness during hospital stay. The loss of muscle thickness was significantly more among patients who died during hospital stay or had adverse outcomes during 90 days following discharge from hospital.

Critically ill patients with sepsis are at increased risk of loss of muscle mass $[4,17]$. Demonstration of trends of the muscle loss is desirable for appropriate risk stratification as well as for any preventive or therapeutic intervention. There are few other studies which have reported the loss of muscle thickness on USG among critically ill patients [10-12]. Our study results further highlighted that loss of muscle is common among critically ill patients and the loss is the greatest during early days of hospitalization (3 days). Therefore, any preventive intervention for muscle wasting should be started at the earliest, probably soon after admission.

The muscle dysfunction has been shown to be an independent risk factor for in-hospital mortality [1, $18,19]$. However, none of the previously published studies on muscle thickness on USG reported the data related to muscle thickness and outcomes [1012]. Probably, this is the first study that has reported the data regarding the relationship between loss of muscle thickness and in-hospital and post-discharge outcomes. Importantly, the decline in muscle thickness on USG was able to differentiate survivors from non-survivors as early as day 3 of hospitalization. Among critically ill patients in addition to muscle loss, multiple factors including age and gender of the patient, severity of illness, standard of care and associated co-morbidities which may affect the survival $[20,21]$. However, these results provided us the objective values of muscle thickness which may be 


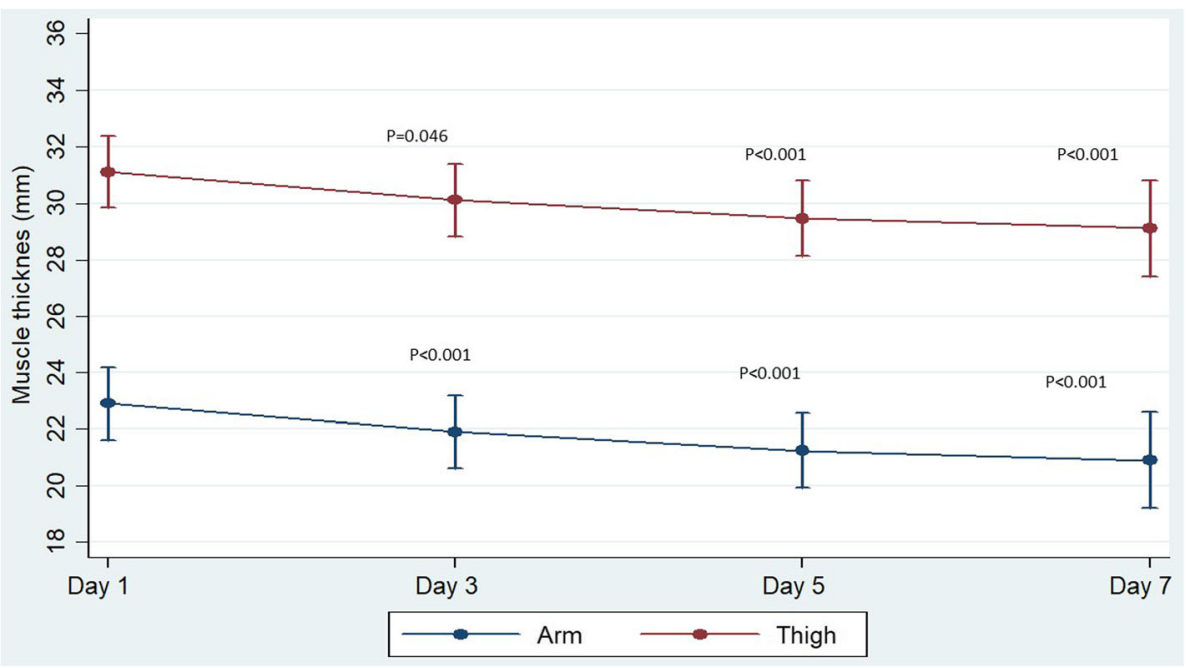

Fig. 2 Trend in muscle thickness in $\mathrm{mm}$ (both the arm and thigh) with $95 \% \mathrm{Cl}$ over days 1, 3, 5 and 7 during hospital stay

Table 2 Decline in arm muscle thickness and outcome

\begin{tabular}{|c|c|c|c|c|}
\hline Muscle thickness & Day 1 & Day 3 & Day 5 & Day 7 \\
\hline \multicolumn{5}{|l|}{ a. In-hospital mortality } \\
\hline Survivors (n) & 59 & 59 & 53 & 28 \\
\hline Muscle thickness (mean $\pm S D$ ) & $23.0 \pm 5.4$ & $22.5 \pm 4.9$ & $21.9 \pm 4.9$ & $21.0 \pm 5.3$ \\
\hline \% Decline [median (IQR)] & NA & $3.5(1.3,5.8)$ & $5.5(2.8,8.8)$ & $4.7(2.7,12.1)$ \\
\hline Non-Survivors (n) & 11 & 11 & 10 & 7 \\
\hline Muscle thickness (mean $\pm \mathrm{SD}$ ) & $21.6 \pm 4.1$ & $19.8 \pm 3.7$ & $19.0 \pm 2.9$ & $18.0 \pm 2.5$ \\
\hline \% Decline [median (IQR)] & NA & $8.8(6.7,10.1)$ & $15.5(13.1,16.4)$ & $19.6(10.7,21.7)$ \\
\hline$p$ value (\% decline) & NA & 0.001 & $<0.001$ & $<0.013$ \\
\hline \multicolumn{5}{|l|}{ b. ICU-acquired weakness } \\
\hline Absent (n) & 55 & 55 & 48 & 23 \\
\hline Muscle thickness (mean $\pm \mathrm{SD}$ ) & $22.4 \pm 5.1$ & $22.0 \pm 4.5$ & $21.5 \pm 4.5$ & $20.5 \pm 4.2$ \\
\hline \% Decline [median (IQR)] & NA & $3.6(1.3,5.8)$ & $5.6(2.8,9.5)$ & $5.6(2.5,11.2)$ \\
\hline Present $(n)$ & 15 & 15 & 15 & 12 \\
\hline Muscle thickness (mean $\pm \mathrm{SD}$ ) & $24.0 \pm 5.9$ & $22.4 \pm 5.8$ & $21.4 \pm 5.9$ & $20.2 \pm 6.4$ \\
\hline \% Decline [median (IQR)] & NA & $6.5(2.7,9.6)$ & $11.8(3.2,17.1)$ & $16.8(4.3,25.7)$ \\
\hline$p$ value (\% decline) & NA & 0.01 & 0.05 & 0.03 \\
\hline \multicolumn{5}{|l|}{ c. 90-day outcome } \\
\hline Stable outcome $(n)$ & 42 & 42 & 36 & 17 \\
\hline Muscle thickness (mean $\pm \mathrm{SD}$ ) & $23.3 \pm 5.6$ & $23.3 \pm 4.8$ & $23.1 \pm 4.8$ & $23.0 \pm 5.2$ \\
\hline \% Decline [median (IQR)] & NA & $2.3(1.0,3.8)$ & $3.6(2.6,5.8)$ & $4.0(2.1,4.4)$ \\
\hline Poor outcome $(n)$ & 17 & 17 & 17 & 11 \\
\hline Muscle thickness (mean $\pm \mathrm{SD}$ ) & $22.2 \pm 5.1$ & $20.5 \pm 4.6$ & $19.3 \pm 4.4$ & $18.0 \pm 3.9$ \\
\hline \% Decline [median (IQR)] & NA & $8.6(5.9,11.1)$ & $13.4(8.8,17.1)$ & $14.4(11.2,17.1)$ \\
\hline$p$ value (\% decline) & NA & $<0.0001$ & $<0.0001$ & 0.0004 \\
\hline
\end{tabular}


Table 3 Decline in thigh muscle thickness and outcome

\begin{tabular}{|c|c|c|c|c|}
\hline Muscle thickness & Day1 & Day3 & Day5 & Day7 \\
\hline \multicolumn{5}{|l|}{ a. In-hospital mortality } \\
\hline Survivors (n) & 59 & 59 & 53 & 28 \\
\hline Muscle thickness (mean \pm SD) & $31.3 \pm 8.5$ & $30.2 \pm 8.3$ & $29.6 \pm 8.0$ & $30.4 \pm 7.4$ \\
\hline \% Decline [median (IQR)] & NA & $2.6(1.4,5.1)$ & $3.7(2.8,8.3)$ & $4.8(3.6,9.8)$ \\
\hline Non-Survivors (n) & 11 & 11 & 10 & 7 \\
\hline Muscle thickness (mean \pm SD) & $30.9 \pm 9.4$ & $28.5 \pm 9.0$ & $27.6 \pm 8.7$ & $26.4 \pm 8.7$ \\
\hline \% Decline [median (IQR)] & NA & $7.5(5.2,11.4)$ & $13.0(10.0,15.7)$ & $15.5(10.4,17.8)$ \\
\hline$p$ value (\% decline) & NA & $<0.001$ & $<0.001$ & $<0.003$ \\
\hline \multicolumn{5}{|l|}{ b. ICU-acquired weakness } \\
\hline Absent $(n)$ & 55 & 55 & 48 & 23 \\
\hline Muscle thickness (mean \pm SD) & $31.5 \pm 8.1$ & $30.3 \pm 7.8$ & $29.9 \pm 7.2$ & $29.9 \pm 6.8$ \\
\hline \% Decline [median (IQR)] & NA & $2.9(1.6,5.2)$ & $3.7(2.9,9.1)$ & $5.1(3.3,10.4)$ \\
\hline Present $(n)$ & 15 & 15 & 15 & 12 \\
\hline Muscle thickness (mean \pm SD) & $30.2 \pm 10.3$ & $28.5 \pm 10.4$ & $27.3 \pm 10.4$ & $28.9 \pm 9.5$ \\
\hline \% Decline [median (IQR)] & NA & $5.7(2.9,8.4)$ & $9.9(5.5,13.0)$ & $11.0(6.5,16.8)$ \\
\hline$p$ value (\% decline) & NA & 0.04 & 0.02 & 0.02 \\
\hline \multicolumn{5}{|l|}{ c. 90-days outcome } \\
\hline Stable outcome $(n)$ & 42 & 42 & 36 & 17 \\
\hline Muscle thickness (mean \pm SD) & $31.7 \pm 7.9$ & $31.0 \pm 7.7$ & $30.9 \pm 7.0$ & $31.6 \pm 6.6$ \\
\hline \% Decline [median (IQR)] & NA & $2.1(-5.0,7.9)$ & $3.1(-2.0,9.6)$ & $4.2(-2.6,9.1)$ \\
\hline Poor outcome (n) & 17 & 17 & 17 & 11 \\
\hline Muscle thickness (mean \pm SD) & $30.1 \pm 9.9$ & $28.2 \pm 9.6$ & $26.8 \pm 9.3$ & $28.5 \pm 8.6$ \\
\hline \% Decline [median (IQR)] & NA & $5.7(0.8,14.4)$ & $9.9(3.5,26.9)$ & $10.9(2.7,33.7)$ \\
\hline$p$ value (\% decline) & NA & $<0.0001$ & $<0.0001$ & 0.0003 \\
\hline
\end{tabular}

useful in the identification of patients who may be at risk of worse in-hospital and 90-day outcomes. Also, this study provided the reference values of muscle thickness for calculation of sample size for any future preventive or therapeutic intervention for the management of muscle dysfunction among patients with sepsis.

Application of MRC score for the diagnosis of ICU-AW is limited by feasibility as well as reliability [22-24]. Our study has demonstrated the relationship between declines in muscle thickness with ICU-AW. These results suggest that USG may be a better tool for early and timely identification of individuals at risk of development of ICU-AW.

This is one of the largest prospective studies demonstrating the feasibility of USG for the assessment of the muscle thickness over time. Also, to the best of our knowledge, this is the first study which has described the relationship between decline in arm and thigh muscle thickness on USG and various in-hospital and post discharge outcomes among critically ill patients with sepsis. We recognize that there are many limitations of this study. First, the sample size was determined based on feasibility. Therefore, the study may not be powered enough to detect an independent relationship between the decline in the muscle thickness and various in-hospital and post-discharge outcomes assessed. Also, the number of study participants decreased significantly after day 7 of recruitment leaving few patients for any meaningful analysis, though, this loss of study participants was not in our control as the reasons for this was either death or discharge. It was a single-centre study, and image acquisition and measurements were done by experienced operator; therefore, one may question its wider application. Measurement of muscle thickness on USG is considered as operator-dependent, and one may question the validity of the measurements. In our experience, inter- and intra-observer reliability for measurements of muscle thickness of the arm and thigh on USG was excellent $[8,9,25]$. It is suggested that before using USG for this purpose, reliability of the measurements must be checked. We could not do echogenicity analysis because of lack of the software required for this. We did not compare the 


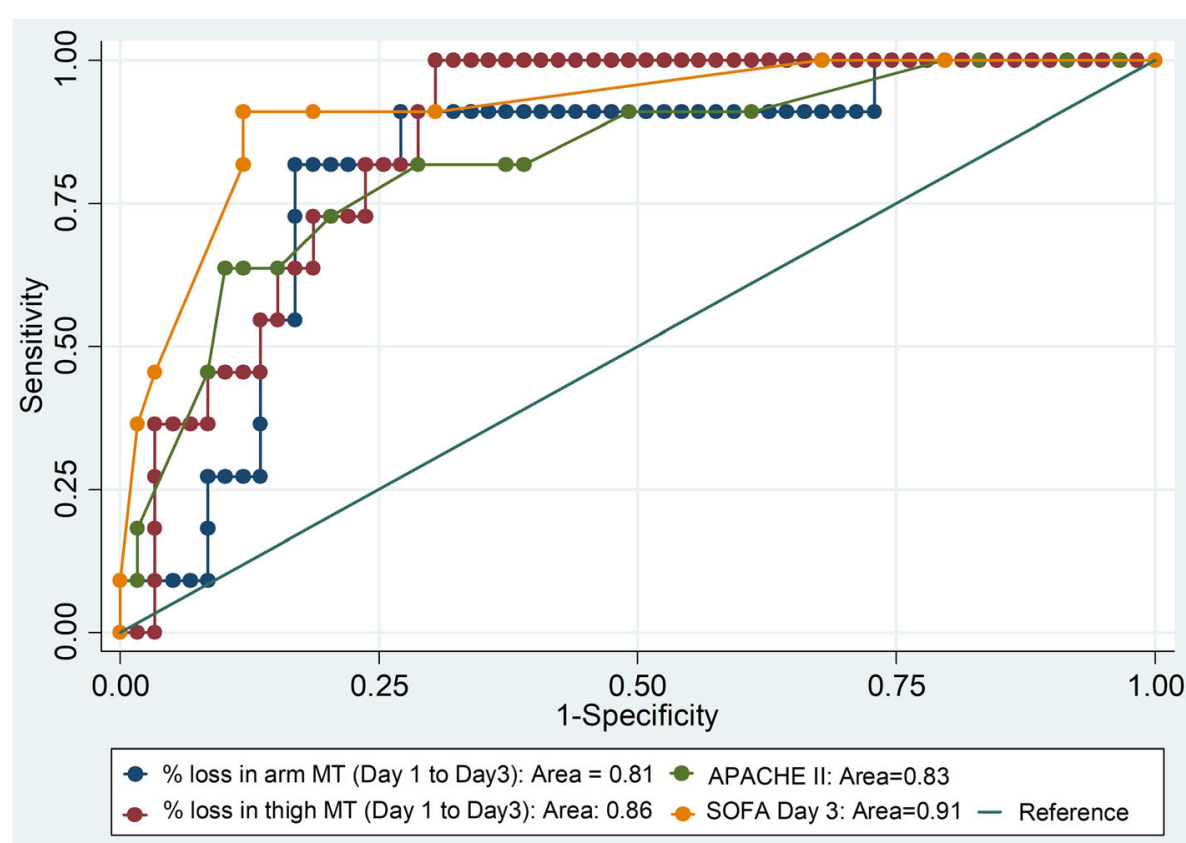

Fig. 3 ROC analysis showing comparison of in-hospital survival predictive ability of percent loss in arm and thigh muscle thickness from days 1 to 3, APACHE score on day 1 and SOFA score on day 3

measurement of thickness on USG with that of thickness measured by other standard tool such MRI, CT scan, or fluoroscopy. Such comparisons are desirable for the assessment of accuracy; however, these are not practical in ICU setting. However, muscle thickness measured using USG correlates well with measurements done with these tools [26]. The muscle biopsy is gold standard for the demonstration of muscle loss. Therefore, demonstration of correlation of muscle thickness on USG and biopsy would have been the best as shown by Puthucheary and colleagues in a landmark study [27]. However, we did not perform muscle biopsy due to its invasive nature. Regardless of inclusion criteria of sepsis, the included patients were more serious with severe sepsis or septic shock. It was probably the result of limited availability of beds due to which only the sickest patients could be admitted. There are certain drugs such as muscle relaxants, corticosteroids, sedatives and aminoglycosides which may affect the muscle functions. We did not record these parameters as our primary objective was to describe the trends, not the predictors of muscle loss. Hence, effects of these drugs on muscle thickness among
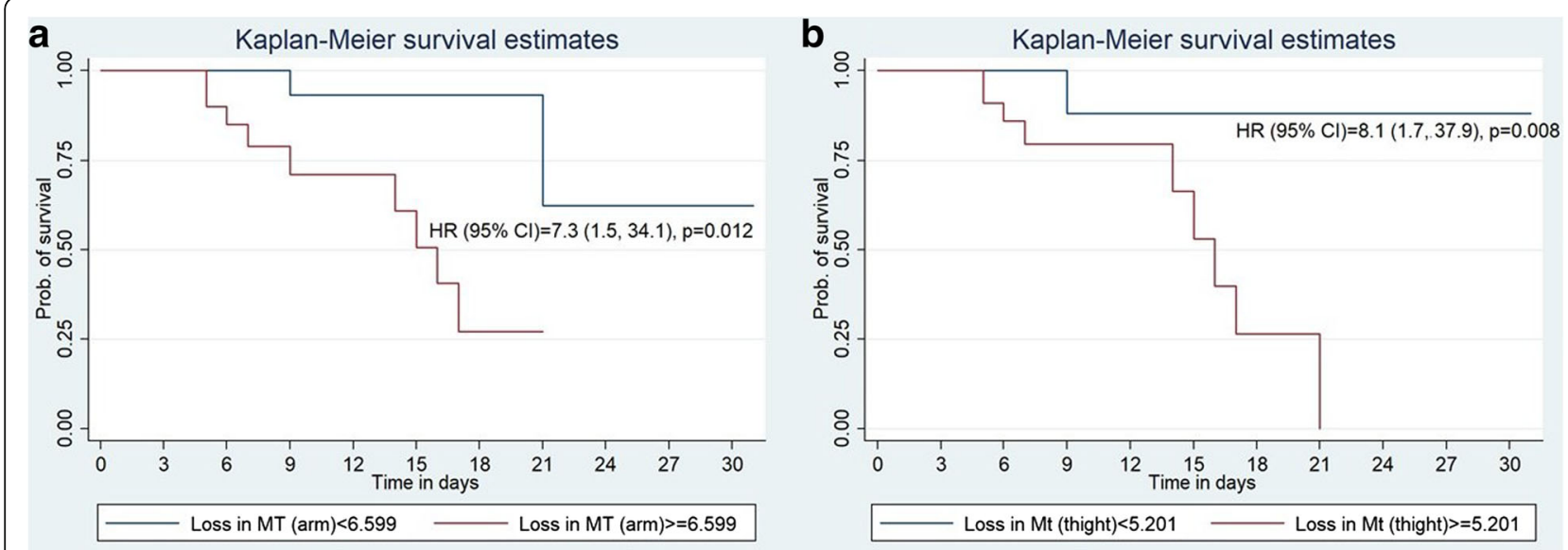

Fig. 4 Kaplan-Meier curve showing probability of survival over 28 days of hospital stay between the two groups of loss in muscle thickness of the arm (a) and the thigh (b) 
Table 4 ROC analysis for in-hospital mortality predictive ability of muscle thickness (MT), APACHE II and SOFA

\begin{tabular}{|c|c|c|c|c|c|}
\hline Variables & Cutoff & Sensitivity & Specificity & LR & Area $(95 \% \mathrm{Cl})$ \\
\hline Loss of arm MT between days 1 and 3 of measurement (\%) & 6.59 & 81.8 & 81.4 & 4.4 & $0.81(0.68,0.94)$ \\
\hline Loss of thigh MT from days 1 to $3(\%)$ & 5.20 & 81.8 & 76.3 & 3.4 & $0.86(0.77,0.95)$ \\
\hline APACHE $\|$ at admission & 19 & 81.8 & 71.2 & 2.8 & $0.83(0.69,0.96)$ \\
\hline SOFA on the day 3 & 5 & 90.9 & 88.1 & 7.7 & $0.91(0.82,1.0)$ \\
\hline
\end{tabular}

these patients could not be commented. Also, we should recognize that the presence of many confounder such as age and gender of the patient, severity of illness, standard of care and associated co-morbidities can affect the both muscle thickness as well as outcomes; however, we could not perform analysis to adjust these due to limited number of events.

\section{Conclusions}

We conclude that USG is a useful tool for serial assessment of muscle thickness in ICU settings. It has a potential to identify the patients at risk of development of ICU-AW, in-hospital mortality and 90-day adverse outcome within a few days of hospitalization.

\section{Additional file}

Additional file 1: Figure S1. Showing real-time frozen image for measurement of the arm muscle thickness of the arm (both biceps and coracobrachialis muscle may be seen). The thickness is measured between superficial fat-muscle interface and periosteum. Figure S2. Measurement of thigh muscle thickness. Figure S3. The marking over the thigh and arm. Figure S4. Kaplan Meier survival curve for change in muscle thickness between days 1 and 3. (DOCX 592 kb)

\section{Abbreviations}

AUC: Area under the curve; USG: Ultrasonography; SD: Standard deviation; ICU: Intensive care unit; HR: Hazard ratio; Cl: Confidence intervals; CT: Computer tomography; MRI: Magnetic resonance imaging; DEXA: Dual energy X-ray absorptiometry; LOS: Length of stay; ICU-AW: ICU-acquired weakness; MRC: Medical Research Council; ROC: Receiver operating characteristics; APACHE: Acute Physiology and Chronic Health Evaluation; SOFA: Sequential Organ Failure Assessment

\section{Acknowledgements}

Not applicable

\section{Funding}

None.

\section{Availability of data and materials}

The datasets used and/or analysed during the current study are available from the corresponding author on reasonable request.

\section{Authors' contributions}

$\mathrm{VH}$ was responsible for the study design, data collection and interpretation and manuscript editing. RK was responsible for the data collection and manuscript writing. GCK was responsible for the study design and manuscript editing. MK was responsible for the statistical analysis. KM was responsible for the study design. PT was responsible for the data interpretation and manuscript writing. SM was responsible for the manuscript revision and data interpretation. AM was responsible for the study design and data interpretation. ASB was responsible for the data acquisition and interpretation. RG was responsible for the study design and data interpretation. All authors read and approved the final manuscript.

\section{Ethics approval and consent to participate}

Study protocol was approved by Institutional Ethics Committee.

\section{Consent for publication}

Not applicable.

\section{Competing interests}

The authors declare that they have no competing interests.

\section{Publisher's Note}

Springer Nature remains neutral with regard to jurisdictional claims in published maps and institutional affiliations.

\section{Author details}

${ }^{1}$ Department of Pulmonary Medicine and Sleep Disorders, All India Institute of Medical Sciences, New Delhi, India. ${ }^{2}$ Department of Biostatistics, All India Institute of Medical Sciences, New Delhi, India. ${ }^{3}$ Department of Radio-diagnosis, All India Institute of Medical Sciences, New Delhi, India.

Received: 30 August 2018 Accepted: 23 November 2018

Published online: 12 December 2018

\section{References}

1. Kress JP, Hall JB. ICU-acquired weakness and recovery from critical illness. $N$ Engl J Med. 2014;370(17):1626-35.

2. Kramer CL. Intensive care unit-acquired weakness. Neurol Clin. 2017; 35(4):723-36.

3. Barreiro E. Models of disuse muscle atrophy: therapeutic implications in critically ill patients. Ann Transl Med. 2018;6(2):29.

4. Baldwin CE, Bersten AD. Alterations in respiratory and limb muscle strength and size in patients with sepsis who are mechanically ventilated. Phys Ther. 2014;94(1):68-82.

5. Jolley SE, Bunnell AE, Hough CL. ICU-acquired weakness. Chest. 2016; 150(5):1129-40

6. Campbell IT, Watt T, Withers D, England R, Sukumar S, Keegan MA, et al. Muscle thickness, measured with ultrasound, may be an indicator of lean tissue wasting in multiple organ failure in the presence of edema. Am J Clin Nutr. 1995:62(3):533-9.

7. Bunnell A, Ney J, Gellhorn A, Hough CL. Quantitative neuromuscular ultrasound in intensive care unit-acquired weakness: a systematic review. Muscle Nerve. 2015;52(5):701-8.

8. Hadda V, Khilnani GC, Kumar R, Dhunguna A, Mittal S, Khan MA, et al. Intra- and inter-observer reliability of quadriceps muscle thickness measured with bedside ultrasonography by critical care physicians. Indian J Crit Care Med. 2017:21(7):448-52.

9. Hadda V, Kumar R, Dhungana A, Khan MA, Madan K, Khilnani GC. Inter- and intra-observer variability of ultrasonographic arm muscle thickness measurement by critical care physicians. J Postgrad Med. 2017;63(3):157-61.

10. Parry SM, El-Ansary D, Cartwright MS, Sarwal A, Berney S, Koopman R, et al. Ultrasonography in the intensive care setting can be used to detect changes in the quality and quantity of muscle and is related to muscle strength and function. J Crit Care. 2015 ;30(5):1151.e9-14.

11. Gruther W, Benesch T, Zorn C, Paternostro-Sluga T, Quittan M, Fialka-Moser $\checkmark$, et al. Muscle wasting in intensive care patients: ultrasound observation of the M. quadriceps femoris muscle layer. J Rehabil Med. 2008;40(3):185-9.

12. Reid CL, Campbell IT, Little RA. Muscle wasting and energy balance in critical illness. Clin Nutr. 2004;23(2):273-80. 
13. Levy MM, Fink MP, Marshall JC, Abraham E, Angus D, Cook D, et al. 2001 SCCM/ESICM/ACCP/ATS/SIS International Sepsis Definitions Conference. Crit Care Med. 2003;31(4):1250-6.

14. Kleyweg RP, van der Meche FG, Schmitz PI. Interobserver agreement in the assessment of muscle strength and functional abilities in Guillain-Barre syndrome. Muscle Nerve. 1991;14(11):1103-9.

15. Declaration of Helsinki. Ethical principles for medical research involving human subjects. J Indian Med Assoc. 2009;107(6):403-5.

16. World Medical Association. World Medical Association Declaration of HelsinkiEthical Principles for Medical Research Involving Human Subjects. JAMA. 2013;310(20):2191-4.

17. Callahan LA, Supinski GS. Sepsis-induced myopathy. Crit Care Med. 2009; 37(10 Suppl):S354-67.

18. Hermans G, Van Mechelen H, Clerckx B, Vanhullebusch T, Mesotten D, Wilmer A, et al. Acute outcomes and 1-year mortality of intensive care unit-acquired weakness. A cohort study and propensity-matched analysis. Am J Respir Crit Care Med. 2014;190(4):410-20.

19. Ali NA, O'Brien JM Jr, Hoffmann SP, Phillips G, Garland A, Finley JC, et al. Acquired weakness, handgrip strength, and mortality in critically ill patients. Am J Respir Crit Care Med. 2008;178(3):261-8.

20. Ho KM, Williams TA, Harahsheh Y, Higgins TL. Using patient admission characteristics alone to predict mortality of critically ill patients: a comparison of 3 prognostic scores. J Crit Care. 2016;31(1):21-5.

21. Li G, Thabane L, Cook DJ, Lopes RD, Marshall JC, Guyatt G, et al. Risk factors for and prediction of mortality in critically ill medical-surgical patients receiving heparin thromboprophylaxis. Ann Intensive Care. 2016:6(1):18.

22. De Jonghe B, Sharshar T, Lefaucheur JP, Authier FJ, Durand-Zaleski I, Boussarsar $\mathrm{M}$, et al. Paresis acquired in the intensive care unit: a prospective multicenter study. JAMA. 2002;288(22):2859-67.

23. Hough CL, Lieu BK, Caldwell ES. Manual muscle strength testing of critically ill patients: feasibility and interobserver agreement. Crit Care. 2011;15(1):R43.

24. Connolly BA, Jones GD, Curtis AA, Murphy PB, Douiri A, Hopkinson NS, et al. Clinical predictive value of manual muscle strength testing during critical illness: an observational cohort study. Critical care (London, England). 2013;17(5):R229.

25. Hadda V, Kumar R, Hussain T, Khan MA, Madan K, Mohan A, et al. Reliability of ultrasonographic arm muscle thickness measurement by various levels of health care providers in ICU. Clin Nutr ESPEN. 2018;24:78-81.

26. Dupont AC, Sauerbrei EE, Fenton PV, Shragge PC, Loeb GE, Richmond FJ. Real-time sonography to estimate muscle thickness: comparison with MRI and CT. J Clin Ultrasound. 2001;29(4):230-6.

27. Puthucheary ZA, Rawal J, McPhail M, Connolly B, Ratnayake G, Chan P, et al. Acute skeletal muscle wasting in critical illness. JAMA. 2013;310(15):1591-600.

Ready to submit your research? Choose BMC and benefit from:

- fast, convenient online submission

- thorough peer review by experienced researchers in your field

- rapid publication on acceptance

- support for research data, including large and complex data types

- gold Open Access which fosters wider collaboration and increased citations

- maximum visibility for your research: over $100 \mathrm{M}$ website views per year

At $\mathrm{BMC}$, research is always in progress.

Learn more biomedcentral.com/submissions 